\title{
Numerical optimisation and experimental validation of divided rail freight brake disc crown
}

\author{
Uroš Grivc $^{1}$ David Deržič ${ }^{1}$ Simon Muhič ${ }^{2,3}$ (B)
}

Received: 11 January 2018/Revised: 18 October 2018/Accepted: 26 October 2018/Published online: 16 November 2018

(C) The Author(s) 2018

\begin{abstract}
In this study, numerical optimisation and experimental validation of a divided rail freight brake disc crown made of grey cast iron EN-GJL-250 is presented. The analysed brake disc is used in rail freight wagons and possesses a load capacity of 22.5 tons per axle. Two of the divided rail freight brake discs are mounted on each axle. With the aid of numerical analysis, the thermal dissipation properties of the brake disc were optimised and ventilation losses were reduced, and the numerical results were compared with experimental results. A one-way fluid-structure interaction analysis was performed. A computational fluid dynamic model of a divided rail freight brake disc, used to predict air flow properties and heat convection, was incorporated into a finite element model of the disc and used to evaluate the temperature of the disc. A numerical parametrical optimisation of cooling ribs of the brake disc was also performed, and novel optimised cooling ribs were developed. A transient thermal numerical analysis of the brake disc was validated using temperature measurements obtained during a braking test on a test bench. The ventilation losses of the brake disc were measured on a test bench specifically designed for the task, and the losses were compared to the simulation results. The experimentally obtained ventilation losses and temperature measurements compared favourably with the simulation
\end{abstract}

Simon Muhič

simon.muhic@guest.arnes.si

1 KOVIS d.o.o., Brezina 102, 8250 Brežice, Slovenia

2 Faculty of Mechanical Engineering, University of Novo mesto, Na Loko 2, 8000 Novo mesto, Slovenia

3 SIMUTEH, Stična 113, 1295 Ivančna Gorica, Slovenia results, confirming that this type of simulation process may be confidently applied in the future. Through systematic optimisation of the divided rail freight brake disc, ventilation losses were reduced by $37 \%$ and the mass was reduced by $21 \%$, resulting in better thermal performance that will bring with it substantial energy savings.

Keywords Divided rail freight brake disc · Computational fluid dynamics - Finite element method - Computer-aided engineering · One-way fluid-structure interaction

\section{Introduction}

Brake discs are an important component found in almost all moving vehicles. Safety and reliability are crucial for braking systems. Several types of brake discs used in rail vehicles are mainly divided into two groups: axle-mounted brake discs and wheel-mounted brake discs. There are also other designs, like separate brake disc axles and endaxle-mounted brake discs. Brake discs are usually made from grey cast iron, nodular cast iron or steel, depending on the loads to which they will be subjected. The use of brake discs prevents the surface of the rolling wheel itself from braking and thus increases the lifespan of and reduces stress on the wheels. Divided brake discs were developed to facilitate replacement of the brake discs, making the process less time consuming and less expensive, as it eliminates the need to disassemble the entire axle assembly. Disassembly of the axle can cause other problems as well, since all of the parts, like the wheels and bearings, are press fit onto the axle, and disassembly risks damaging them. 
The brake discs in rail freight vehicle are subjected to large fluctuations in temperature and must accumulate and dissipate large amounts of energy due to high loads.

Most brake discs are ventilated, which means they possess special cooling ribs that more efficiently dissipate heat into the environment [1]. Various standards present fundamental algorithms for calculations relevant to design of the discs, but these calculations are not always reliable [2]. Brake discs must also withstand additional loads caused by relatively stiff contact between rail and wheel. Rail stiffness is an important factor for safe operation of the train [3].

Computer-aided engineering (CAE) is often used to predict the performance of automotive brake discs. Ventilated and full brake discs were compared using CAE in [4]. The cooling ribs are located between two friction plates through which air flows in the positive radial direction, dissipating heat. It was observed that up to $77 \%$ of the heat was dissipated by the cooling ribs in a drag brake scenario [4]. On the other hand, in an emergency stop scenario, this number is smaller, as the cooling area of the rib is heated up less due to there being too little time to conduct heat towards the cooling ribs. The dissipation percentage depends on the braking regime, since it is time- and temperature-dependent.

Only the use of modern CAE tools enables products like brake discs to be optimised. CAE involves the extensive use of computer software to assist in engineering tasks and analyses and is ever evolving in engineering practice. It includes software for analysis of structures using finite element analysis (FEA), software for analyses in the field of computational fluid dynamics (CFD), and the study of coupled physical phenomena. These analyses are very important for developing products of better quality. Engineers perform these analyses in the early development stage, during which a virtual prototype of the product is made. Next, it is analysed and, if necessary, optimised to obtain the best product, which is then sent for production. For virtual engineering, we require a reliable, high-performance software package that enables such analyses, as well as high-performance computers to process numerical data. Product development using these tools reduces development costs and enables the company to be more competitive by reducing the time needed to develop and send a final product to market. The application of CAE in virtual environment is widespread in engineering and includes railway optimisation [2, 5-8]. A study on the use of CFD to determine aerodynamic forces showed that CFD simulations are very useful for prediction of real properties [9]. Despite the fact that CAE simulations have become widespread, there has been relatively little research on brake discs in rail vehicles.
Yevtushenko et al. [10] proved that the results from measurements agree well with predictions from finite element method (FEM) simulations of brake discs. Grzes et al. [11] proposed a numerical-experimental scheme for the analysis of temperature in a railway braking system based on FEM model results, which included brake disc-brake pad contact surfaces and interface heat distribution. Adamowicz and Grzes [12] evaluated the impact of the convective mode of heat transfer on the thermal behaviour of a disc brake system during repetitive braking at constant velocity using a fully three-dimensional FEM model and investigated the issue of non-uniform frictional heating effects. The highlights from [12] can be confirmed by the FEM simulations performed in this paper. In another study, Adamowicz and Grzes [13] studied and compared the temperature distributions caused by mutual sliding of two members of the disc brake system using two- and threedimensional FEM modelling techniques; they concluded that FEM simulations enable temperature variations in a real brake disc to be predicted. Belhocine et al. [4] analysed the thermal behaviour of full and ventilated brake discs of vehicles; numerical simulation of the coupled transient thermal field and stress field was carried out by a sequential thermal-structural coupled method and the results obtained by the simulation were satisfactory compared with those from the literature.

Despite many instances of the application of numerical tools on brake discs, there is no research on the simultaneous optimisation of heat transfer, using FEM, and fluid flow, using CFD, as presented in this article. Similarly, no research can be found on the ventilation losses (drag) caused by rotation of the brake disc in a moving vehicle, which causes unwanted energy losses. The ventilation losses of a braking disc are defined in this paper, and simulation results of the ventilation losses were validated with measurements using a novel device.

\section{Methods}

The CAE optimisation started with an initial design, already an optimised version of its predecessor, of a brake disc produced by KOVIS. The brake disc used for this study had a width of $170 \mathrm{~mm}$, an outer diameter of $590 \mathrm{~mm}$, an inner diameter of $325 \mathrm{~mm}$ and an thickness of $10 \mathrm{~mm}$ of wear material. These dimensions were fixed throughout the optimisation. The initial weight of the brake disc assembly was $145 \mathrm{~kg}$. The main goal of the optimisation was to reduce the mass and ventilation losses while increasing the safety factor. These goals would further increase the energy efficiency of rail freight transportation and reduce noise and vibrations. 


\subsection{Governing equations}

The CFD model is solved using the finite volume method, in which the computational domain is divided into small volumes. The conservation equations for each volume are integrated to obtain a system of discrete algebraic equations that are iteratively solved. The mathematical model used to describe a given physical problem is a set of integral-differential equations, constitutive relations and initial and boundary conditions. The basic equations of fluid dynamics are derived from [14]:

Conservation of mass

$\frac{\partial \rho}{\partial t}+\nabla \cdot(\rho \boldsymbol{v})=S_{\mathrm{m}}$.

Conservation of momentum

$\frac{\partial}{\partial t}(\rho \boldsymbol{v})+\nabla \cdot(\rho \boldsymbol{v} \boldsymbol{v})=-\nabla p+\nabla \cdot(\overline{\bar{\tau}})+\rho \boldsymbol{g}+\boldsymbol{F}$.

Conservation of energy

$$
\begin{aligned}
& \frac{\partial}{\partial t}(\rho E)+\nabla \cdot(\boldsymbol{v}(\rho E+p)) \\
& \quad=\nabla \cdot\left(k_{\mathrm{eff}} \nabla T-\sum_{j} H_{j} \boldsymbol{J}_{j}+\left(\overline{\bar{\tau}}_{\mathrm{eff}} \cdot \boldsymbol{v}\right)\right)+S_{\mathrm{h}} .
\end{aligned}
$$

Equation (1) is the general form of the mass conservation equation and is valid for incompressible as well as compressible flows, where $\rho$ represents the density of the fluid, $t$ represents time, $v$ represents the fluid velocity vector, and the source $S_{\mathrm{m}}$ represents the mass added to the continuous phase. In Eq. (2), $p$ is pressure, $\overline{\bar{\tau}}$ is the stress tensor, $\boldsymbol{g}$ is the gravity acceleration vector, and $\boldsymbol{F}$ is gravitational body force. In Eq. (3), $k_{\text {eff }}$ is the effective conductivity, $\boldsymbol{J}_{j}$ is the diffusion flux of species $j, \overline{\bar{\tau}}_{\text {eff }}$ is the deviatoric stress tensor, and $E$ represents energy. The first three terms on the right-hand side of Eq. (3) represent energy transfer due to conduction, species diffusion, and viscous dissipation, respectively; $S_{\mathrm{h}}$ is volumetric heat source.

For transient FEM analysis, the linear system can be defined in matrix form as follows [15]:

$\boldsymbol{C} \dot{\boldsymbol{T}}+\boldsymbol{K} \boldsymbol{T}=\boldsymbol{Q}(t)$,

where $\boldsymbol{C}$ represents the specific heat matrix, $\boldsymbol{T}$ is the temperature vector and $\dot{\boldsymbol{T}}$ is its time derivative, $\boldsymbol{K}$ is the thermal conductivity matrix, and $\boldsymbol{Q}(t)$ is the time-dependent heat flow rate vector.

\subsection{Numerical analysis}

The simulation started as a CFD problem, analysed using the commercial software package Ansys CFX, to obtain the wall heat transfer coefficient at a fixed angular velocity.
The results from the CFD simulation were transferred to a transient thermal simulation made with software Ansys Mechanical, where thermal radiation was also considered. After the temperatures of the brake disc were obtained, it was possible to perform further structural analysis to obtain the deformation and stress caused by thermal expansion. Figure 1 represents the process path of the one-way fluidstructure interaction (FSI) simulation that was performed.

The computational domain was meshed by Ansys software. Meshing was performed using a hybrid mesh in which most of the volume was structured mesh, and the smaller part surrounding the fins was unstructured mesh. The area along the fins and tubes, where convection heat transfer takes place, was covered with 18 inflation layers, each with a thickness of $2.5 \mathrm{~mm}$. These inflation layers were used to capture high velocity, pressure and temperature gradients in the near-wall region, as our main results from the simulation included the wall heat transfer coefficient contour and the forces acting on the walls which cause ventilation losses.

For the CFD numerical model, the Reynolds-averaged Navier-Stokes (RANS) modelling approach was used. To model turbulence in the Ansys CFX software, the $k-\omega$ shear stress transport (SST) turbulence model was used, where $k$ represents the turbulence kinetic energy and $\omega$ represents the specific rate of dissipation, as there are two types of flow in the computational domain. The first type of flow occurs at a relatively large distance from the model, as the domain is relatively large when the $k-\varepsilon$ model is used, where $\varepsilon$ represents the rate of dissipation of turbulence energy. The second type of flow-the more important of the two-occurs near the wall, where the $k-\omega$ model is used. This model includes a transitional blending function, improved reattachment and automatic wall treatment, which is suited for a wide range of dimensionless wall distance $y+$ values, switching to $k-\omega$ near the wall [16]. In addition to the aforementioned model, an equivalent sand grain roughness height of $70 \mu \mathrm{m}$ was used. Consideration of wall roughness is often left out in engineering simulations, even though it has been found to be an important parameter for the results of numerical simulations [17]. Convergence of the simulation required the residuals to be less than 0.00005 and the monitoring points for ventilation losses and other thermal properties to be constant. A second-order double-precision solver was used.

The numerical domain in the CFD analysis was divided into four volumes (Fig. 2), allowing for more varieties of numerical mesh and better control of the individual portions of the domain.

A hexahedral mesh was used in three subdomains that were not part of the brake disc surfaces. A tetrahedral mesh was generated for the centre subdomain, which did include brake disc surfaces. This was done to better capture the 

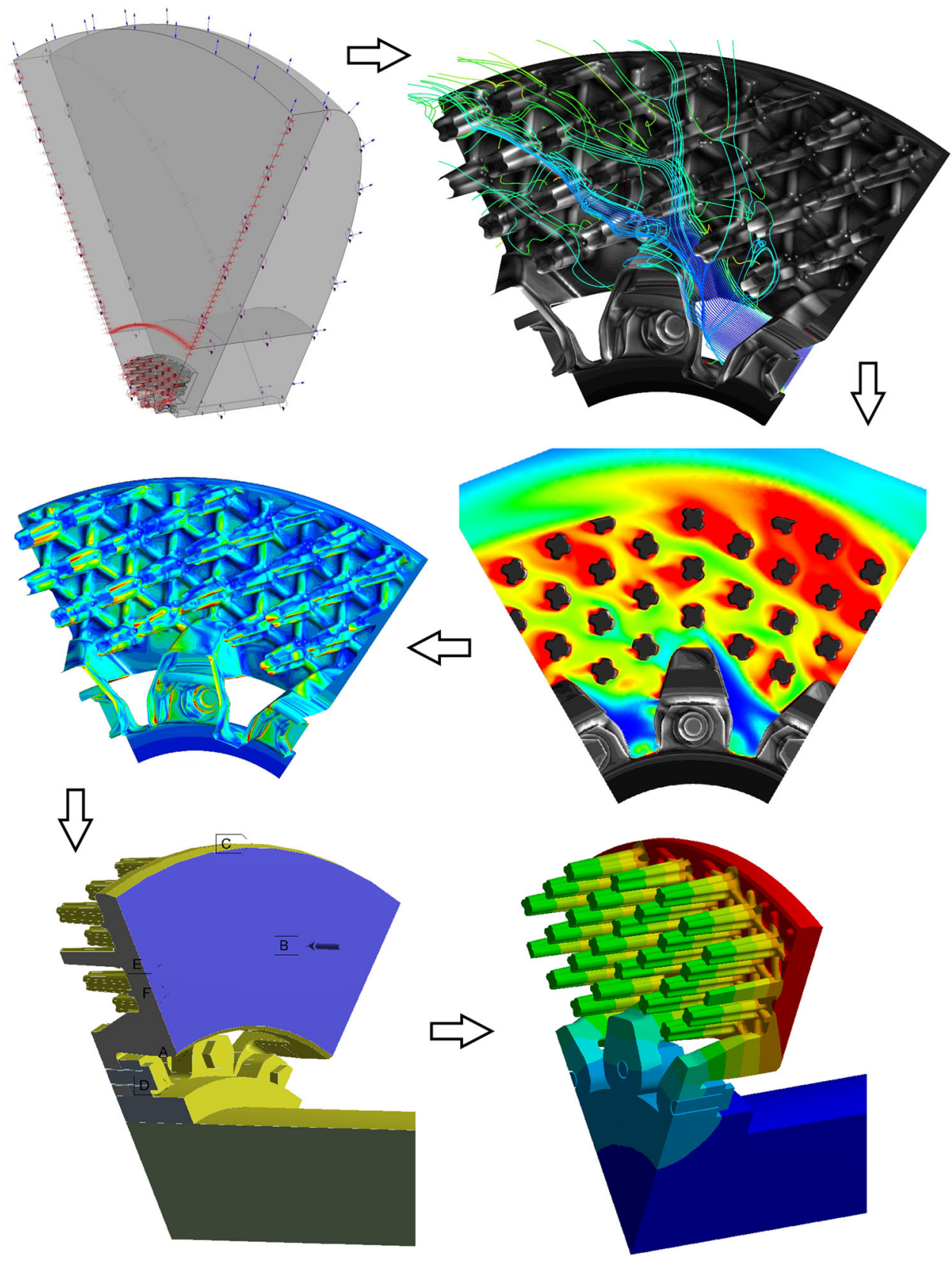

Fig. 1 Simulation process

flow properties near the wall, as the inflation function seen in Fig. 3 was used in the model, allowing proper hosting of the mesh at the walls. By successively refining the mesh, a solution independent of the computational mesh was found. Three mesh densities, with 2.5, 8 and 13.5 Mio nodes, respectively, were tested. In the final analysis, we used the mesh with 13.5 Mio nodes (4.2 Mio tetrahedrons, 8.3 Mio wedges, 0.01 Mio pyramids, and 1 Mio hexahedrons). Three domain sizes were also tested, in which the surfaces furthest from the brake disc, as seen in Fig. 2, were used as an opening-type boundary condition in the CFD simulation. These opening surfaces were varied by $\pm 50 \%$ from the amount shown in Fig. 2. The domain size chosen for the final simulation had the opening surfaces located $0.5 \mathrm{~m}$ in the axial and $1.4 \mathrm{~m}$ in radial directions, respectively, from the brake disc surface.

The wall heat transfer was simulated with a CFD simulation. This simulation included all of the surfaces of the assembled parts: brake disc, hub, fasteners and an axle. The CFD simulation of wall heat transfer was performed at different angular velocities corresponding to the speed of the train up to a speed of $165 \mathrm{~km} / \mathrm{h}$. This value corresponds to $100 \mathrm{rad} / \mathrm{s}$ for a wheel diameter of $0.92 \mathrm{~m}$. The temperature of the walls of the brake disc was held constant at 

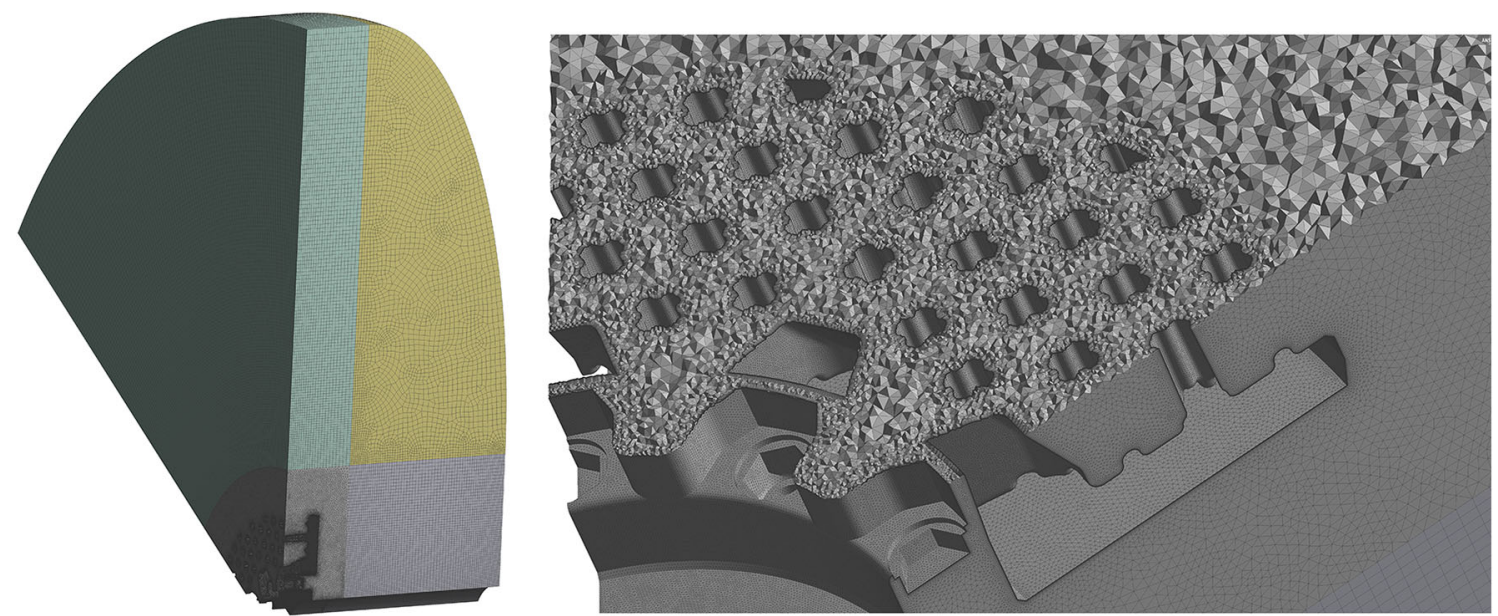

Fig. 2 Numerical mesh
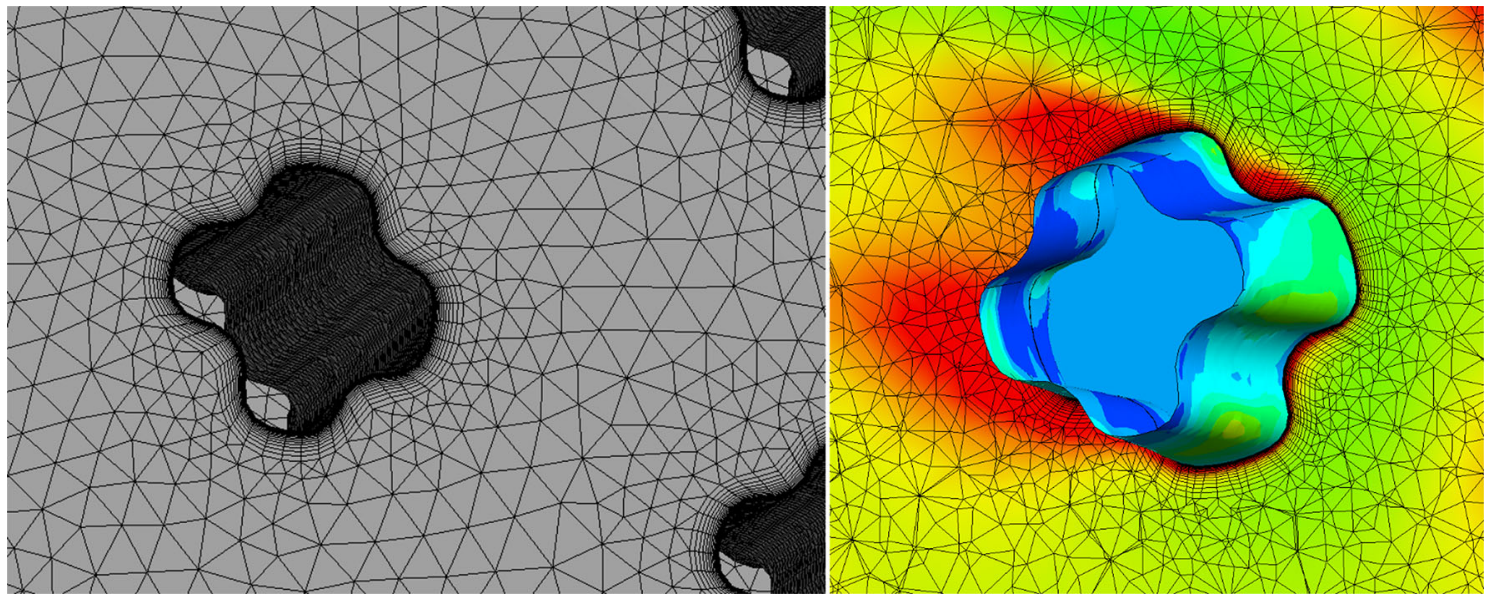

Fig. 3 Detail of numerical mesh near heat transfer surfaces with inflation layers

$100{ }^{\circ} \mathrm{C}$. The temperature of the surroundings was set to $25{ }^{\circ} \mathrm{C}$. The heat flow into the brake disc included a heat distribution factor of 0.89 [18], with which it is assumed that $11 \%$ of the energy is absorbed by the brake pads.

Figure 4 shows the mesh used for the transient thermal simulation. Parts with simple geometry, like the bolts and the axle, were meshed with hexahedral elements. The brake disc and hub were meshed with tetrahedral elements. The brake disc also included 5 inflation layers under the friction surface, which is the face at which the total heat flow input boundary condition was set and where the highest temperature gradients were expected.

The numerical transient thermal simulation predicts behaviour of the brake disc during the braking of a train travelling downhill at a constant velocity of $70 \mathrm{~km} / \mathrm{h}$. This value corresponds to $42.27 \mathrm{rad} / \mathrm{s}$ for a wheel diameter of $0.92 \mathrm{~m}$. The material properties of the brake discs, like the thermal capacity and thermal conductivity, were taken from standard [11]. The thermal properties used in the simulation were temperature-dependent. The heat transfer

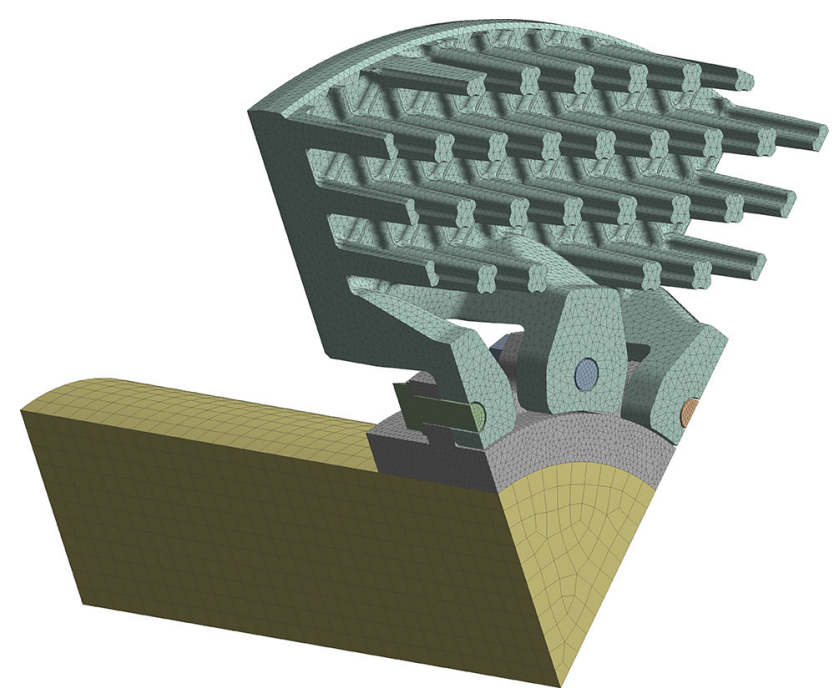

Fig. 4 Numerical mesh used for transient thermal analysis 
coefficient (HTC) contour at $42.27 \mathrm{rad} / \mathrm{s}$ was transferred from the CFD simulation to a transient thermal simulation. Constant thermal inputs of 20, 30 and $40 \mathrm{~kW}$ were used for the brake disc friction surfaces, and a brake disc-brake pad distribution factor of 0.89 [18] was included. A radiation coefficient of $0.43[19,20]$ was used for friction surfaces.

\section{Optimisation of the design}

In the first simulations of the initial design, it was observed that heat is conducted relatively slowly towards the centre of the brake disc. Little heat is conducted towards the centre of the brake disc when the train stops in the emergency stop scenario. The main idea behind optimisation was to more quickly conduct heat away from the friction surfaces. A higher level of heat conduction from the friction plates was achieved by increasing the heat flux behind the friction plate and by increasing the cross-sectional area at the base of the cooling ribs. During the simulation process, some effort was also put into optimising the topology of the heat conduction paths [21], from which the main parameters for heat conduction were determined. It was noticed that the ribs could be optimised by altering the location and shape of the fins. Optimisation was achieved by creating small, hyperbolically shaped cooling ribs and low-profile ribs (Fig. 5).

The height $H_{\mathrm{r}}$, diameter $D_{\mathrm{r}}$ and base radius $\left(H_{\mathrm{p}}, W_{\mathrm{p}}\right.$, $R_{\text {ho }}$ ) of the cooling ribs were carefully tuned during the optimisation process (Fig. 5). Figure 6 presents three different types of small cooling ribs. This particular shape was chosen based on the parametric optimisation. Approximately 280 different heights and shapes of hyperbolic radii were simulated. The definition of parametric optimisation simulation included input shape parameters and output parameters like mass, average wall heat transfer coefficient, thermal power dissipation, and probe temperatures.
The resulting response surface enabled us to select the optimal design. The final design of the low-profile cooling ribs was chosen based on the braking application. In Fig. 6, the final design (middle), which has the best heat flux to weight ratio, is presented. The final design is most effective on brake discs wider than $120 \mathrm{~mm}$. With optimisation, the average wall heat transfer coefficient of the brake discs' cooling rib area rose from 56 to $64 \mathrm{~W} /\left(\mathrm{m}^{2} \cdot \mathrm{K}\right)$ at an angular velocity of $50 \mathrm{rad} / \mathrm{s}$. This is an increase of more than $12 \%$.

\section{Optimisation of ventilation losses}

Ventilation losses represent a loss of energy of the moving train due to drag caused by airflow through the brake disc. Ventilation losses are caused by the rotation of the brake disc, hub and bolts through the air. The brake disc cooling fins act like a centrifugal air pump. This helps to cool the brake disc more quickly, as it drives in more fresh air from the surroundings. Power for the air circulation comes from the wheel axle, as all the braking components are mounted directly on the axle. All rotating surfaces cause drag, a phenomenon that consists of viscous forces and pressure forces. The friction plate produces much less drag than the cooling fins or the hub, whose walls rotate in a direction normal to the air flow. From the CFD simulations, it was observed that, on average, $75 \%$ of ventilation losses come from the cooling fins, $20 \%$ from the disc hub and bolts, and only $5 \%$ from the frictional plate. The ventilation losses consist of forces acting on the surfaces of the brake disc components. Ventilation loss is calculated from ventilation moment as follows:

$P_{\mathrm{L}}=T_{\mathrm{M}} \cdot \omega_{\mathrm{a}}$,

where $P_{\mathrm{L}}$ represents the ventilation losses $(\mathrm{W}), T_{\mathrm{M}}$ is the ventilation moment and $\omega_{\mathrm{a}}$ is the angular velocity.

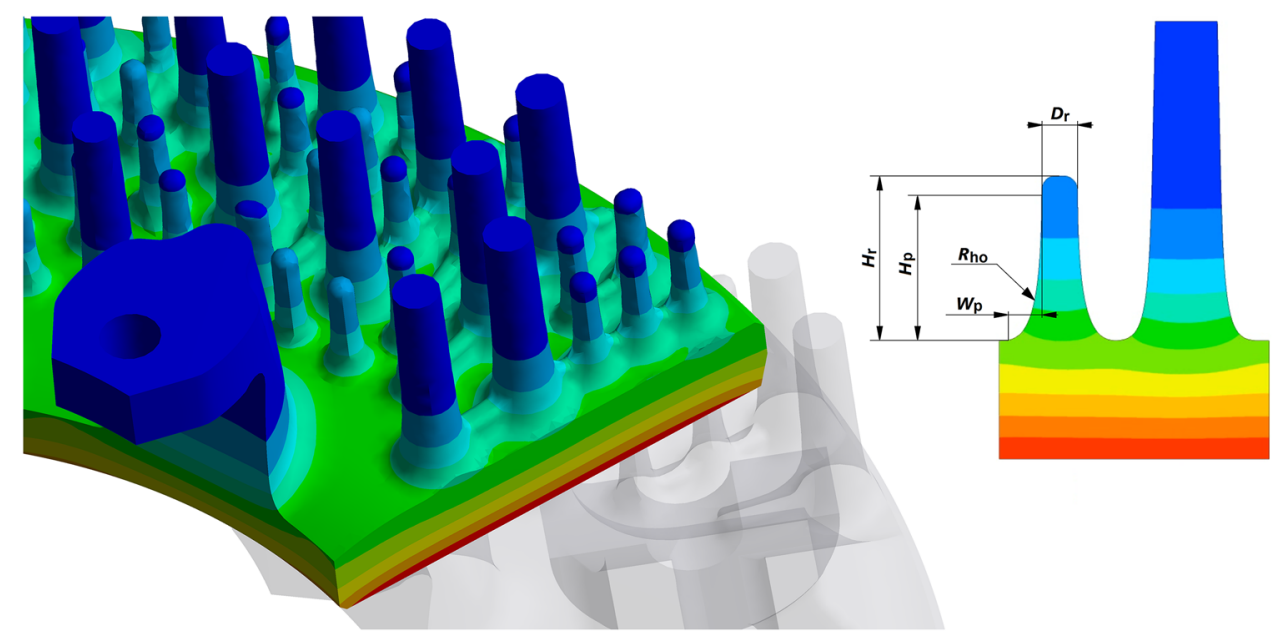

Fig. 5 Representation of low-profile cooling ribs 


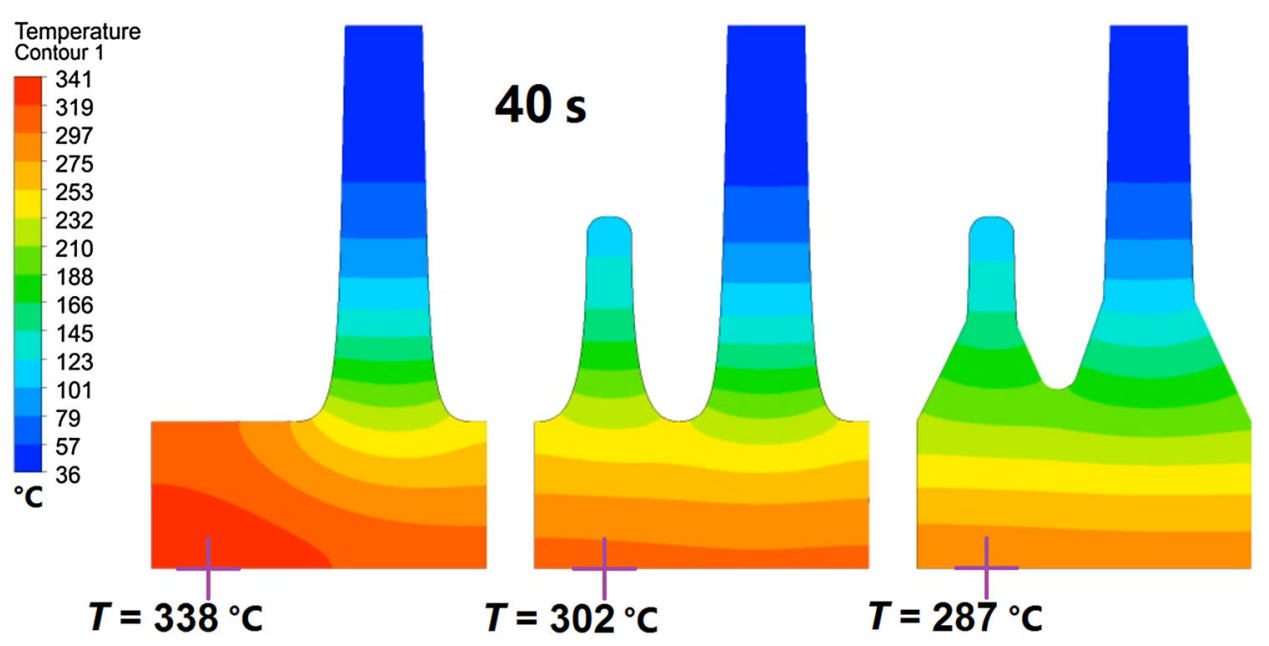

Fig. 6 Representation of braking with and without small cooling ribs at the end of an emergency stop scenario where power input is the highest and stopping time the shortest

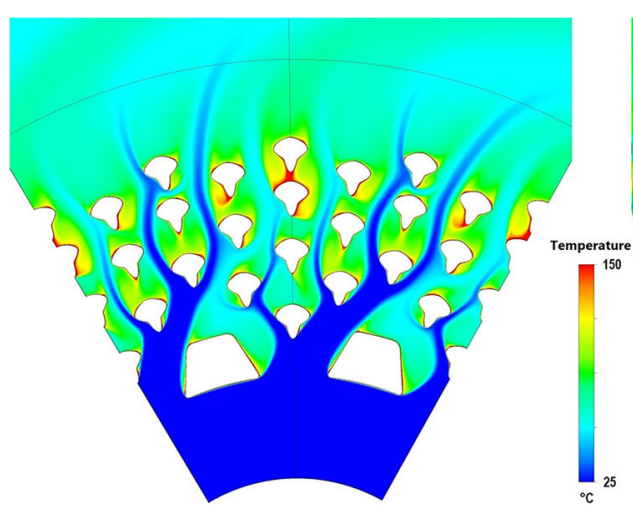

Fig. 7 Two different designs: high drag (left) and low drag (right)

Figure 7 represents the air temperature contour around the cooling ribs of a high-drag and low-drag design. It also represents a two-dimensional CFD simulation used for optimisation of the cooling rib shape. This simulation was performed as a parametric design simulation, with the goal of determining the properties of different shapes of cooling ribs. The high-pressure zone in front of the rib was reduced. It was also observed that a relatively thin boundary layer formed at the front and bottom faces. This thin boundary layer increases the average wall heat transfer coefficient.

\section{Results and discussion}

\subsection{Thermal results}

The results of the transient thermal simulation temperature were compared to the real measured temperatures from previous tests [22]. The drag brake test results for thermal dissipation and thermal capacity properties were obtained

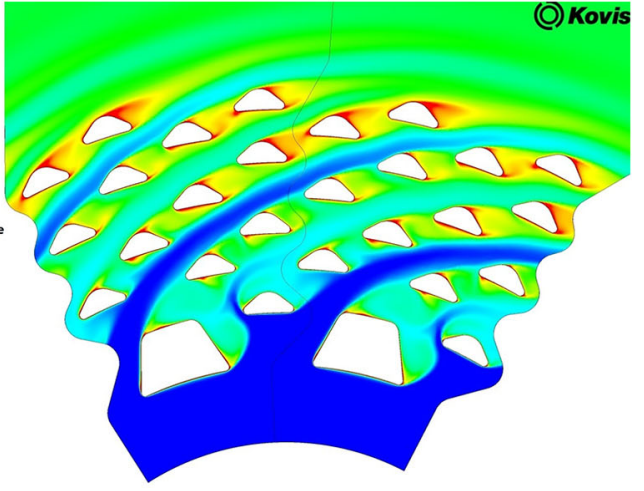

for a train rolling down a $2.1 \%$ gradient slope at a speed of $70 \mathrm{~km} / \mathrm{h}$ with constant braking over a period of $34 \mathrm{~min}$ with a constant power input. The test bench for validating the brake disc design consisted of a rotating main shaft supported by bearings on which brake discs were mounted, as well as an electric motor and flywheels. The brake calliper was mounted on a device able to freely rotate around the main shaft. Rotation of the brake calliper was constrained by a load cell that was used for braking torque measurements. The angular velocity of the brake disc was constant throughout the braking process. Three separate tests were conducted for each of the three power input levels $(20,30$, and $40 \mathrm{~kW})$, which, respectively, represent total energy levels of:

- Level $1=>20 \mathrm{~kW}$ drag brake $=>40.8 \mathrm{MJ}$.

- Level $2=>30 \mathrm{~kW}$ drag brake $=>61.2 \mathrm{MJ}$.

- Level $3=>40 \mathrm{~kW}$ drag brake $=>81.6 \mathrm{MJ}$.

Figure 8 shows a comparison of the average temperatures obtained from the real tests and the simulation during 


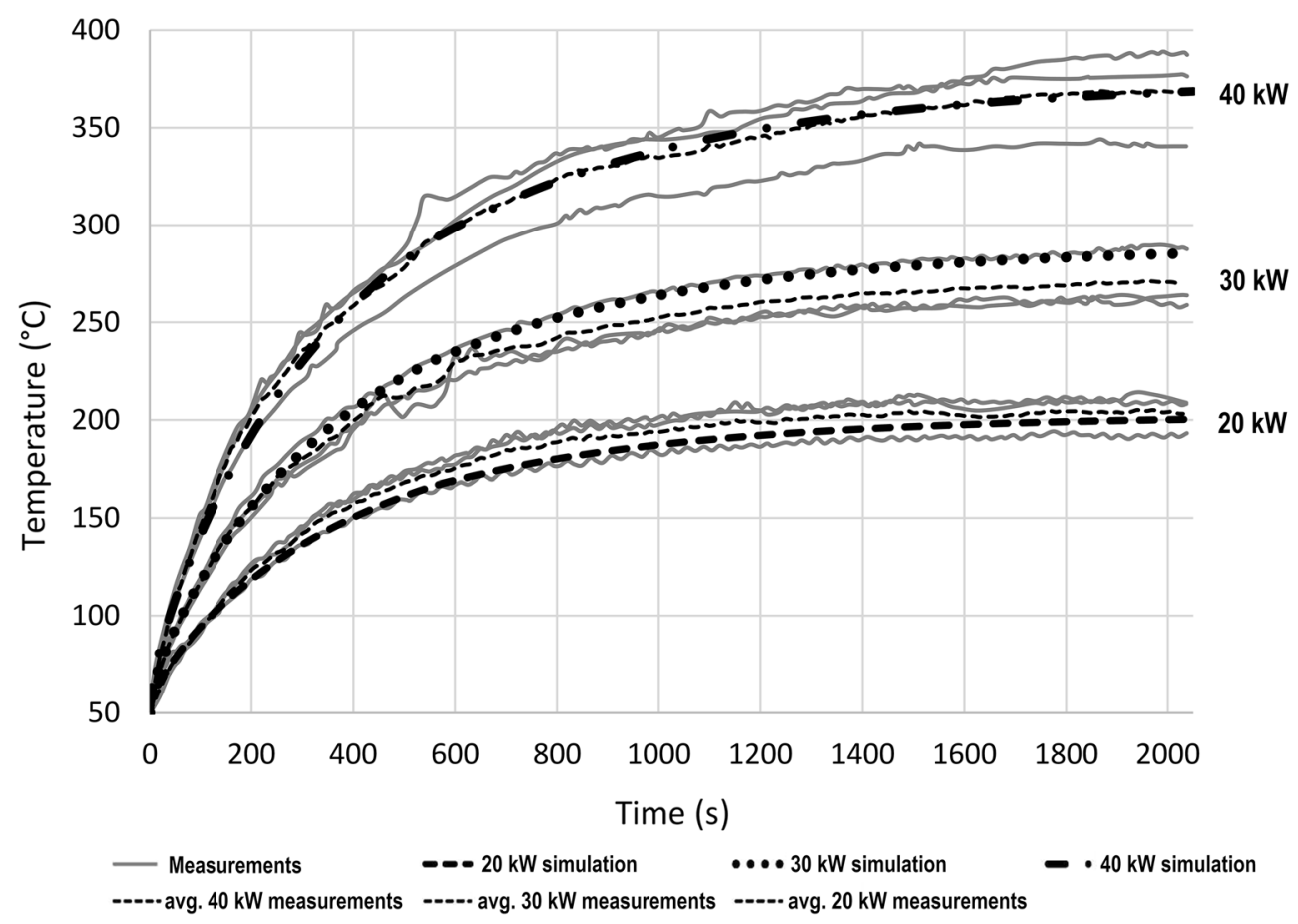

Fig. 8 Comparison of temperatures obtained from test and simulation for the initial design of a brake disc in a drag brake application

a drag brake scenario. The light grey lines represent averaged temperatures from actual measurements. An average of these three tests was performed later and is represented by thin dashed lines for each of the 3 power levels. The three separate lines marked "simulation" represent the temperatures obtained from the transient thermal simulation. It can be observed that the lines corresponding to the average empirical measurement and the simulated values are very close to one another, indicating that the simulation accurately represents the drag brake scenario. The material (grey cast iron EN-GJL-250) used for the simulation is produced by KOVIS. Its thermal properties, like thermal conductivity and thermal capacity, are temperature-dependent, a fact that is taken into consideration $[23,24]$. The temperature distribution at separate time points is represented in Fig. 9.

Empirical measurements of temperature were obtained with $6 \mathrm{~K}$-type thermocouples $1 \mathrm{~mm}$ beneath the surface; these measurements were averaged [25]. The average temperature from the simulation was also obtained at a distance $1 \mathrm{~mm}$ beneath the surface. K-type thermocouples have an accuracy of $\pm 2.2{ }^{\circ} \mathrm{C}$ or $\pm 0.75 \%$, whichever is greater.

\subsection{Ventilation loss results}

It was observed that the initial design had relatively high ventilation losses, since it was designed to have good thermal dissipation properties. A device was specifically constructed to measure ventilation losses. The device consisted of an electric motor driven by a frequency inverter, an axle on which the brake disc was mounted, sensors for measuring the reaction moment of the electric motor, and a precise tachometer. The reaction torque was measured at 10 separate steady-state angular velocity steps. The data logger obtained measurements at a frequency of $3 \mathrm{~Hz}$. A total of 3600 measurements of the reaction moment were obtained at each step, and an average value for the steps was calculated. The repeatability of the measurements was within $\pm 1.5 \% \mathrm{~W}$ at $100 \mathrm{rad} / \mathrm{s}$. This simulation included multiple steady-state simulations at six different angular velocities: 5, 25, 42.27, 50, 75, $100 \mathrm{rad} / \mathrm{s}$. Figure 10 shows that the final design reduced ventilation losses by $37 \%$, which was somewhat better than the $32 \%$ predicted by the simulation. This was achieved by incorporating low-drag profile cooling ribs into the final design, as well as the new low-profile hyperbolic ribs. A noticeable amount of energy will be conserved due to this reduction in ventilation loss.

\section{Conclusion}

Numerical simulations were carried out with the goal of optimising important parameters, and measurements of the initial and final designs of the divided rail freight brake disc crown were obtained. During the simulations, many important parameters were analysed, and considerable 

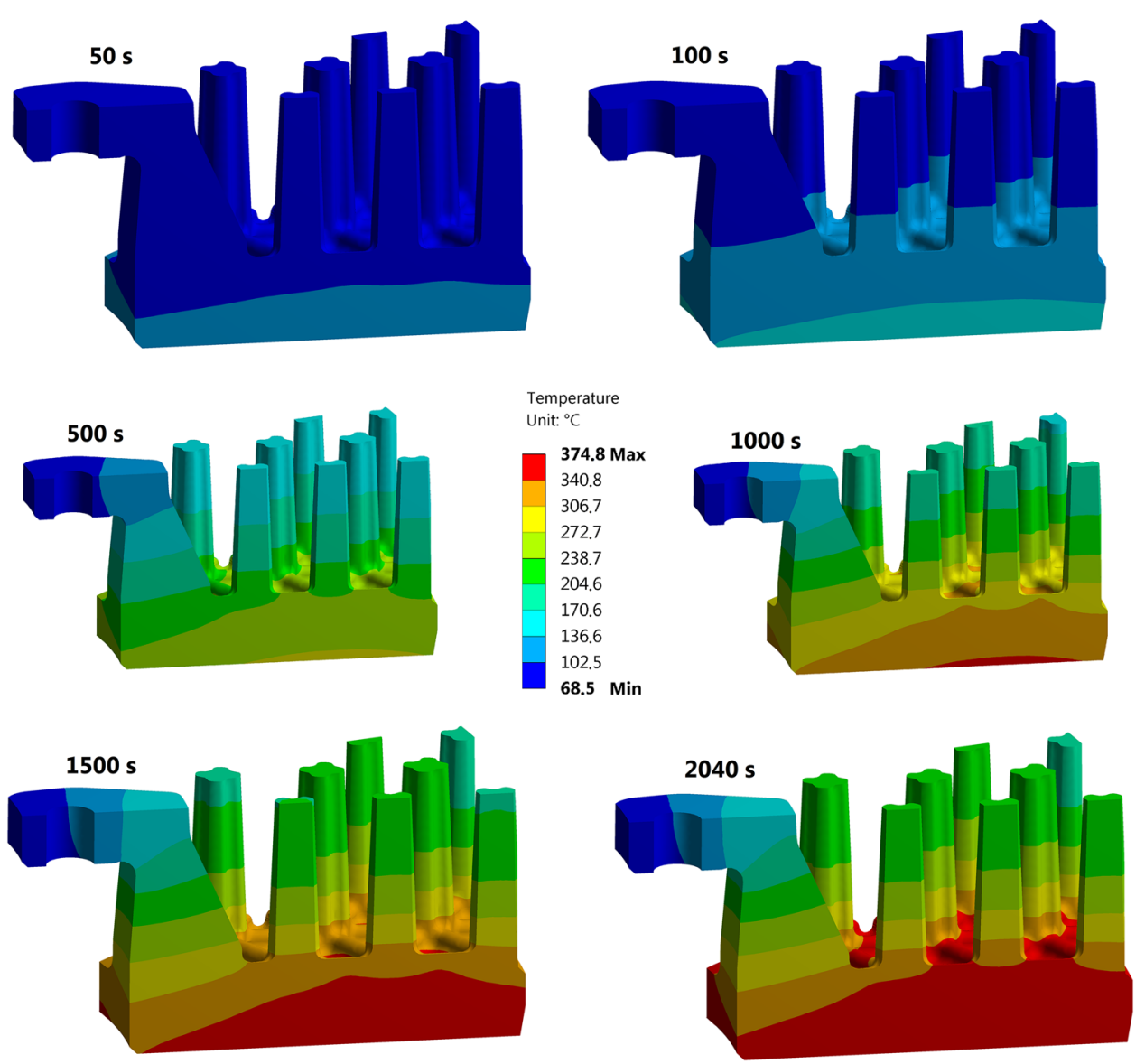

Fig. 9 Temperature distribution for the drag brake scenario

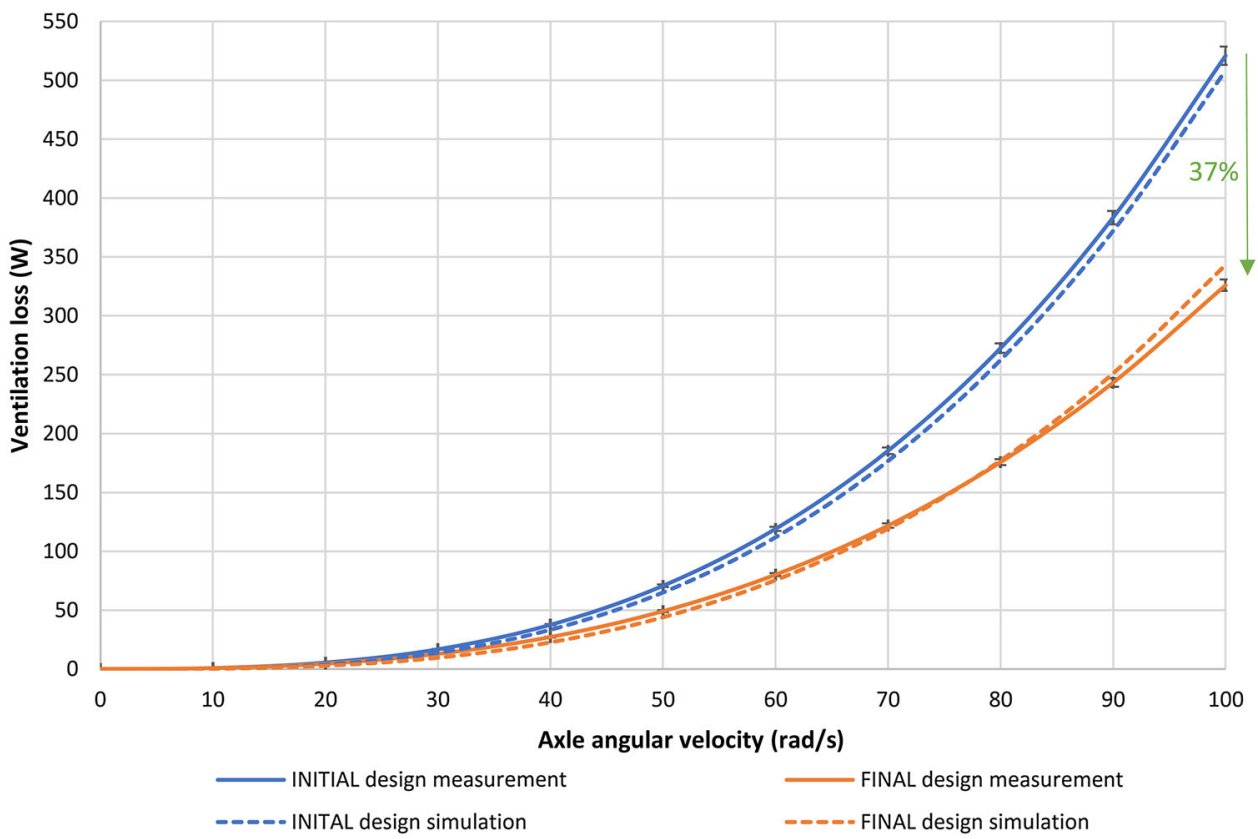

Fig. 10 Comparison of measured and simulated ventilation losses 
improvements to the initial design were made. The CFD simulations of the brake disc assembly compared favourably with experimental measurements, with regard to ventilation losses. The CFD simulations also provided excellent results with regard to wall heat transfer, which were, in turn, used in the one-way fluid-structure interaction simulation for transient thermal analysis. The transient thermal simulation of the divided rail freight brake disc crown also agreed well with experimentally measured temperatures.

With CAE and numerical optimisation of the divided rail freight brake disc crown design, ventilation losses were reduced by $37 \%$, and the mass of the disc was reduced by $21.5 \%$, providing better heat dissipation. The optimised design will help save energy, since the brake disc is more efficient. Furthermore, less energy will be needed for the production and acceleration of the new brake disc, permitting the wagon to carry additional load.

Acknowledgements This work was supported by the European Union's Horizon 2020 research and innovation programme FUTURA under Grant Agreement No. 700985. The authors gratefully acknowledge funding and support from the project.

Open Access This article is distributed under the terms of the Creative Commons Attribution 4.0 International License (http:// creativecommons.org/licenses/by/4.0/), which permits unrestricted use, distribution, and reproduction in any medium, provided you give appropriate credit to the original author(s) and the source, provide a link to the Creative Commons license, and indicate if changes were made.

\section{References}

1. Grive U (2016) Numerical simulation of thermal and structural loads in rolling stock brake disc. Bachelor thesis, University of Maribor

2. Pugi L, Malvezzi M, Papini S, Vettori G (2013) Design and preliminary validation of a tool for the simulation of train braking performance. J Mod Transp 21:247-257. https://doi.org/10.1007/ s40534-013-0027-6

3. Wang P, Wang L, Chen R et al (2016) Overview and outlook on railway track stiffness measurement. J Mod Transp 24:89-102. https://doi.org/10.1007/s40534-016-0104-8

4. Belhocine A, Bouchetara M (2014) Structural and thermal analysis of automotive disc brake rotor. Arch Mech Eng. https://doi. org/10.2478/meceng-2014-0005

5. Mulligan QA, Barimani M, Green SI (2016) Full-scale freight train underbody aerodynamics with application to track spraying. Int J Rail Transp 4:151-166. https://doi.org/10.1080/23248378. 2016.1176545

6. Götz G, Polach O (2017) Verification and validation of simulations in a rail vehicle certification context. Int J Rail Transp. https://doi.org/10.1080/23248378.2017.1412839

7. Xiang H, Li Y, Wang B, Liao H (2015) Numerical simulation of the protective effect of railway wind barriers under crosswinds. Int J Rail Transp 3:151-163. https://doi.org/10.1080/23248378. 2015.1054906
8. Papini S, Pugi L, Rindi A, Meli E (2013) An integrated approach for the optimization of wheel-rail contact force measurement systems. J Mod Transp 21:95-102. https://doi.org/10.1007/ s40534-013-0013-z

9. Asress MB, Svorcan J (2014) Numerical investigation on the aerodynamic characteristics of high-speed train under turbulent crosswind. J Mod Transp 22:225-234. https://doi.org/10.1007/ s40534-014-0058-7

10. Yevtushenko AA, Kuciej M, Grzes P, Wasilewski P (2017) Temperature in the railway disc brake at a repetitive short-term mode of braking. Int Commun Heat Mass Transf 84:102-109. https://doi. org/10.1016/J.ICHEATMASSTRANSFER.2017.04.007

11. Grzes P, Oliferuk W, Adamowicz A et al (2016) The numericalexperimental scheme for the analysis of temperature field in a pad-disc braking system of a railway vehicle at single braking. Int Commun Heat Mass Transf 75:1-6. https://doi.org/10.1016/J. ICHEATMASSTRANSFER.2016.03.017

12. Adamowicz A, Grzes P (2011a) Influence of convective cooling on a disc brake temperature distribution during repetitive braking. Appl Therm Eng 31:2177-2185. https://doi.org/10.1016/J. APPLTHERMALENG.2011.05.016

13. Adamowicz A, Grzes P (2011b) Analysis of disc brake temperature distribution during single braking under non-axisymmetric load. Appl Therm Eng 31:1003-1012. https://doi.org/10.1016/J. APPLTHERMALENG.2010.12.016

14. ANSYS Inc. (2016) ANSYS CFX theory guide. Release 17.2. Help System. ANSYS Inc.

15. ANSYS Inc. (2016) Theory Reference for the mechanical APDL. Release 17.2. Help System. ANSYS Inc.

16. Pevec M (2013) Prediction method of thermal fatigue crack initiation on automotive brake discrubbing surface. Dissertation, University of Maribor

17. Lipej A, Muhič S, Mitruševski D (2017) Wall roughness influence on the efficiency characteristics of centrifugal pump. Stroj Vestn J Mech Eng 639:529-536. https://doi.org/10.5545/sv-jme. 2017.4526

18. Grześ P (2011) Partition of heat in $2 \mathrm{~d}$ finite element model of a disc brake. Acta Mech Autom 5:35-41

19. Trevenet J, Siroux M, Desmet B (2008) Brake disc surface temperature measurement using a fiber optic two-color pyrometer. In: 9th international conference on quantitative infrared thermography. Krakow, Poland, 2-5 July 2008

20. Thevenet J, Siroux M, Desmet B (2010) Measurements of brake disc surface temperature and emissivity by two-color pyrometry. Appl Therm Eng 30:753-759. https://doi.org/10.1016/j. applthermaleng.2009.12.005

21. Cheng C-H, Chen Y-F (2014) Topology optimization of heat conduction paths by a non-constrained volume-of-solid function method. Int J Therm Sci 78:16-25. https://doi.org/10.1016/J. IJTHERMALSCI.2013.11.011

22. Řezníček R, Gerlici J (2016) Testing of kovis Disc $590 \times 170$, CI, drawing Nr. K-1-14-113-00 according to project FUTURA. Report no. S-102-047/16. Žilina

23. SIST EN 1561 (2011) Founding-grey cast irons. 35

24. Koetniyom S, Brooks PC, Barton DC (2002) The development of a material model for cast iron that can be used for brake system analysis. Proc Inst Mech Eng Part D J Automob Eng 216:349-362. https://doi.org/10.1243/0954407021529165

25. Sawczuk W (2015) The evaluation of a rail disc brake braking process by using a thermal camera. Meas Autom Monit $61: 265-270$ 